Full Paper

\title{
Voltammetric Behavior of Antileukemia Drug Glivec. Part III: In Situ DNA Oxidative Damage by the Glivec Electrochemical Metabolite
}

\author{
Victor Constantin Diculescu, ${ }^{\mathrm{a}}$ Marilene Vivan, ${ }^{\mathrm{b}}$ Ana Maria Oliveira Brett*a \\ a Departamento de Química, Faculdade de Ciências e Tecnologia, Universidade de Coimbra, 3004-535 Coimbra, Portugal \\ *e-mail: brett@ci.uc.pt \\ b Hospital da Universidade de Coimbra, 3000 Coimbra, Portugal
}

Received: June 16, 2006

Accepted: June 22, 2006

\begin{abstract}
Glivec is a relatively small molecule with activity against the protein tyrosine kinase, a protein expressed by all patients with chronic myelogenous leukemia (CML). Based on its activity on CML, glivec is undergoing extensive evaluation of its activity against other types of tumor. As a result, there is an ongoing need for clarification of glivec pharmacokinetics so that issues such as drug-biomolecular complex interactions can be understood.

The interaction of DNA with the antileukemia drug glivec was investigated in bulk solution and at a dsDNAelectrochemical biosensor using differential pulse voltammetry. It was found that glivec binds to dsDNA and this interaction leads to modifications in the dsDNA structure, electrochemically recognized through changes of the anodic oxidation peaks of guanosine and adenosine bases. The dsDNA-biosensor enabled the in situ electrochemical generation of glivec redox metabolites and the detection of DNA oxidative damage. Using polynucleotides of known sequence it has been proved that the interaction between glivec and DNA takes place at adenine enriched segments. The generation of glivec oxidation product inside the DNA double helix leads to oxidation of adenine residues and the electrochemical detection of 2,8-dihydroxyadenine. An interaction mechanism is proposed and the formation of 2,8-dihydroxyadenine is explained.
\end{abstract}

Keywords: Glivec, Chronic myelogenous leukemia (CML), Electrochemistry, Differential pulse voltammetry, DNA, Oxidative damage, Adenine, 2,8-Dihydroxyadenine

DOI: $10.1002 /$ elan.200603602

\section{Introduction}

Chronic myeloid leukemia (CML) is a malignancy characterized by an elevated number of white blood cells. Cytogenetic studies performed decades ago $[1,2]$ correlated the disease with the presence of the abnormal Philadelphia chromosome $[3,4]$. The consequence is the creation of a $B C R-A B L$ fusion protein, a constitutively active cytoplasmic protein-tyrosine kinase [5-6].

CML, at least in the stable phase, is unique among malignancies in that the malady appears to be the result of a single major biochemical defect, the $B C R-A B L$ protein. In contrast, most malignancies are the result of several genetic and biochemical lesions [7-8]. Additional mutations account for CML progression from a stable phase to the accelerated and blast phases. The $B C R-A B L$ oncoprotein thus represents a unique drug target. Purification of the $B C R-A B L$ protein and X-ray crystallography of the tyrosine kinase domain led to the design of a small molecule that could bind and block the phosphorylation of kinase activity [9-10].

Glivec (Gleevec, STI 571 or imatinib mesylate), Scheme 1, a derivative of 2-phenylaminopyrimidine, is believed to competitively inhibit the binding of ATP by interacting with the ATP-binding site of tyrosine kinases [11]. This inhibits the ability of $A B L$ to transfer phosphate groups from ATP and phosphorylate tyrosine residues on substrate proteins, which in turn prevents the transduction of energy signals necessary for ABL-induced cellular proliferation and apoptosis. Thus, the specific signal transduction pathway abnormally activated in the leukemic transformation process is inactivated by glivec while the normal pathways are unaffected. Clinical trials demonstrated the ability of glivec to induce hematologic and cytoge-<smiles>CC1C=CC(NC(=O)c2ccc(CN3CCN(C)CC3)cc2)=CC1Nc1nccc(-c2cccnc2)n1</smiles>

Scheme 1. Glivec chemical structure. 
netic remissions in patients in chronic phase as well as in accelerated phase of CML.

Being a relatively new drug, there are only few references about glivec in the specialized literature and most deal with the analytical determination of glivec and its main metabolite in urine or human plasma and are based on liquid chromatography tandem mass spectrometry and electrophoretic methods [12-17].

Recently, using an alkaline comet assay, it was shown that glivec at concentrations ranging from 0.2 to $2 \mu \mathrm{M}$ induces DNA damage in human leukemic cells expressing the $B C R$ $A B L$ protein [18]. Also, it was demonstrated that glivec did not induce DNA strand breaks in the direct interaction with DNA but rather alkali-labile sites. Moreover, the pretreatment of the $B C R-A B L$ protein expressing cells with vitamins $A, C$ and $E$ reduced the extent of DNA damage evoked by glivec. It was shown that the mechanism of the antileukemic action of glivec may involve not only the inhibition of $B C R-A B L$, but also DNA damage in the cells expressing this fusion protein.

Based on its activity on CML, glivec is undergoing extensive evaluation for its activity against other tumor types [19-21]. As a result of these evaluations there is an ongoing need for estimation of glivec pharmacokinetics so that issues such as drug-biomolecular complex interactions can be evaluated.

In the past decade, there has been great interest in the development of DNA based biosensors. An electrochemical sensor for DNA damage consists of an electrode with DNA immobilized on the surface. Interactions of surface-immobilized DNA (either by electrostatic adsorption or by evaporation) with the damaging agent are converted, via changes in electrochemical properties of the DNA recognition layer, into measurable electrical signals. Such a kind of device has been successfully applied to study the interaction of several substances with dsDNA and the interpretation of the results contributed to the elucidation of the mechanisms by which DNA is damaged by hazardous compounds [22-25].

In this context, the aim of the present paper is concerned with the electrochemical study of the in situ interaction of glivec with dsDNA immobilized on a glassy carbon electrode surface. Several situations were studied using a dsDNA modified glassy carbon electrode i.e. the DNAelectrochemical biosensor. The experimental results presented here give strong evidence that by controlling the electrode potential it is possible to detect not only modifications to the dsDNA structure but also damage to purinic bases that occurs during redox processes of glivec metabolites, electrochemically generated on the biosensor surface.

\section{Experimental}

\subsection{Reagents}

Glivec capsules of $100 \mathrm{mg}$ imatinib were obtained from Novartis. Double stranded DNA (dsDNA), single stranded
DNA (ssDNA) and polyadenilic (poly[A]) and polyguanilic (poly[G]) acids were obtained from Sigma and used without further purification. Stock solutions of $100 \mu \mathrm{M}$ glivec, and $60 \mu \mathrm{g} \mathrm{mL}{ }^{-1}$ dsDNA, ssDNA, poly[A] and poly[G] were prepared in $\mathrm{pH} 4.50 .1 \mathrm{M}$ acetate buffer electrolyte. All solutions were prepared using analytical grade reagents and purified water from a Millipore Milli-Q system (conductivity $\leq 0.1 \mu \mathrm{S} \mathrm{cm}^{-1}$ ).

Microvolumes were measured using EP-10 and EP-100 Plus Motorized Microliter Pipettes (Rainin Instruments Co. Inc., Woburn, USA). The $\mathrm{pH}$ measurements were carried out with a GLP 21 Crison $\mathrm{pH}$ meter. All experiments were done in $\mathrm{pH} 4.5,0.1 \mathrm{M}$ acetate buffer at room temperature $\left(25 \pm 1^{\circ} \mathrm{C}\right)$.

\subsection{Voltammetric Parameters and Electrochemical Cells}

Voltammetric experiments were carried out using a $\mu$ Autolab running with GPES version 4.9 software, Eco-Chemie, Utrecht, The Netherlands. The experimental conditions for differential pulse voltammetry (DPV) were: pulse amplitude $50 \mathrm{mV}$, pulse width $70 \mathrm{~ms}$, scan rate $5 \mathrm{mV} \mathrm{s}^{-1}$. An equilibration time of 5 seconds was always allowed before each DPV scan. All measurements were carried out using a glassy carbon (GCE) $(d=1.5 \mathrm{~mm})$ working electrode, a Pt wire counter electrode, and a $\mathrm{Ag} / \mathrm{AgCl}(3 \mathrm{M} \mathrm{KCl})$ as reference, in a $0.5 \mathrm{~mL}$ one-compartment electrochemical cell.

\subsection{GCE Pretreatment}

The GCE was polished using diamond spray (particle size $1 \mu \mathrm{m})$ before every electrochemical experiment. After polishing, the electrode was rinsed thoroughly with MilliQ water for $30 \mathrm{~s}$; then it was sonicated for 1 minute in an ultrasound bath and again rinsed with water. After this mechanical treatment, the GCE was placed in $\mathrm{pH} 4.50 .1 \mathrm{M}$ acetate buffer electrolyte and various DP voltammograms were recorded until a steady state baseline voltammogram was obtained. This procedure ensured very reproducible experimental results.

\subsection{DNA Biosensors Preparation and Incubation Procedure}

The dsDNA-biosensors were prepared by successively covering the $\operatorname{GCE}(d=1.5 \mathrm{~mm})$ surface with three drops of $5 \mu \mathrm{L}$ each of $60 \mu \mathrm{g} \mathrm{mL}{ }^{-1} \mathrm{dsDNA}$ solution. After placing each drop on the electrode surface the biosensor was dried under a constant flux of $\mathrm{N}_{2}$. The ssDNA, poly[A] and poly[G]-modified GCE were prepared in the same way.

Incubation with glivec was always carried out by holding the biosensor during 2 minutes (unless stated otherwise) in a solution containing $5 \mu \mathrm{M}$ glivec in $\mathrm{pH} 4.50 .1 \mathrm{M}$ acetate buffer. During this period of time the solution was 
continuously stirred. Then, the electrode was rinsed with deionized water to ensure the removal of unbound molecules and transferred to acetate buffer where transduction was performed, always using DPV.

\subsection{Adsorption of Glivec Oxidation Product at the GCE Surface}

A pretreated GCE was held for 2 minutes in a solution of $5 \mu \mathrm{M}$ glivec in $\mathrm{pH} 4.50 .1 \mathrm{M}$ acetate buffer. Then, the electrode was washed with deionized water in order to remove the unbound glivec molecules and placed in an electrochemical cell containing only the supporting electrolyte. A potential of $+0.90 \mathrm{~V}$ was applied during 2 minutes to enable the oxidation of glivec molecules adsorbed at the GCE surface.

\subsection{Acquisition and Presentation of Voltammetric Data}

All the voltammograms presented were backgroundsubtracted and baseline-corrected using the moving average application with a step window of $5 \mathrm{mV}$ included in GPES version 4.9 software. This mathematical treatment improves the visualization and identification of peaks over the baseline without introducing any artifact, although the peak intensity is in some cases reduced $(<10 \%)$ relative to that of the untreated curve. Nevertheless, this mathematical treatment of the original voltammograms was used in the presentation of all experimental voltammograms for a better and clearer identification of the peaks.

\section{Results and Discussion}

\subsection{Voltammetry of Glivec at a GCE}

The electrochemical behavior of adsorbed glivec at the GCE surface, was briefly revisited in order to make it easier to identify the peaks occurring after glivec-dsDNA interaction.

The DP voltammogram obtained in $\mathrm{pH} 4.50 .1 \mathrm{M}$ acetate buffer after free adsorption for 2 minutes in a solution of $5 \mu \mathrm{M}$ glivec is shown in Figure $1 \mathrm{~A}-$ full line. The oxidation peak $1_{\mathrm{a}}$ of glivec occurs at $E_{\mathrm{pa}}^{1}=+0.87 \mathrm{~V}$ and is followed by another peak $2_{\mathrm{a}}$ at $E_{\mathrm{pa}}^{2}=+1.20 \mathrm{~V}$.

In a further experiment, after adsorption of glivec, the GCE was conditioned at $+0.90 \mathrm{~V}$ during 2 minutes in $\mathrm{pH} 4.5$ $0.1 \mathrm{M}$ acetate buffer. This procedure enabled the oxidation of the adsorbed glivec molecules on the GCE surface. The DP voltammogram obtained in buffer, Figure 1A, dotted line, shows a new peak $3_{\mathrm{a}}$ at $E_{\mathrm{pa}}^{3}=+0.32 \mathrm{~V}$. This peak corresponds to oxidation of the glivec oxidation product, $\mathrm{P}_{\text {glivec }}$, adsorbed on the electrode surface. At the same time, the oxidation current of glivec peak $1_{\mathrm{a}}$ decreases due to the compound consumption during the conditioning procedure.
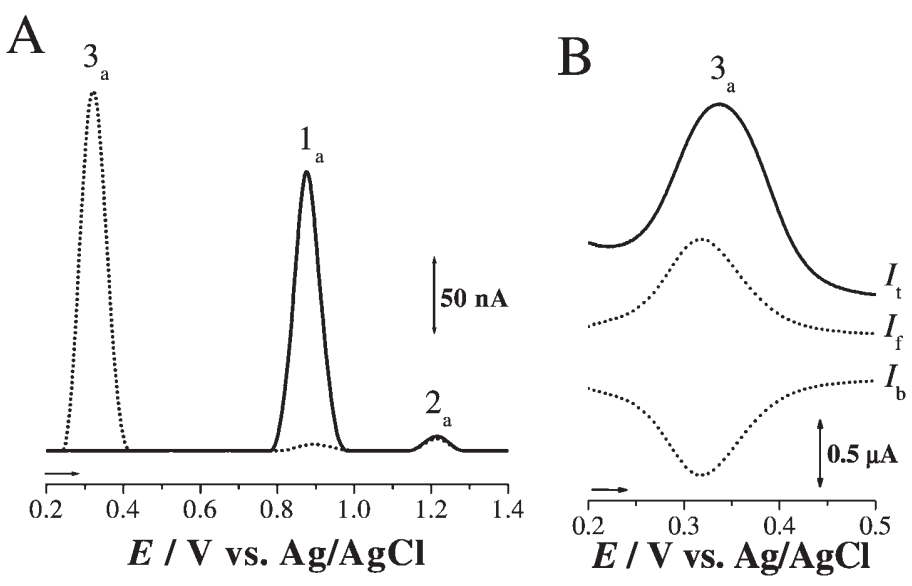

Fig. 1. A) DP voltammograms obtained with a GCE in $\mathrm{pH} 4.5$ $0.1 \mathrm{M}$ acetate buffer after free adsorption in $5 \mu \mathrm{M}$ glivec (-) without and $(\cdots \cdots)$ with application of $+0.90 \mathrm{~V}$ during 2 minutes. B) SW voltammogram obtained in $\mathrm{pH} 4.50 .1 \mathrm{M}$ acetate buffer after adsorption of $P_{\text {glivec }}$ at the GCE surface (more details in Sec. 2.5). $I_{\mathrm{t}}$ : total current, $I_{\mathrm{f}}$ : forward current and $I_{\mathrm{b}}$. backward current; $f=25 \mathrm{~Hz}, \Delta E_{\mathrm{s}}=1 \mathrm{mV}$ thus $v_{\text {effective }}=25 \mathrm{mV} \mathrm{s}^{-1}$.

Peak $2_{\text {a }}$ maintains the same current as in the previous experiment.

In a third experiment, $\mathrm{P}_{\text {glivec }}$ was adsorbed at the electrode surface as described in Section 2.5. Then, a SW voltammogram was recorded in $\mathrm{pH} 4.50 .1 \mathrm{M}$ acetate buffer (Fig. 1B). The reversibility of the oxidation of $\mathrm{P}_{\text {glivec }}$ is demonstrated by plotting the forward and backward components of the total current, where the oxidation and the reduction currents are equal, Figure 1B. The identical value of the potential of peak $3 \mathrm{a}$ in the forward and on the backward current components is an indication of the adsorption of glivec oxidation product at the GCE surface [26]. Moreover, $\mathrm{P}_{\text {glivec }}$ remains adsorbed at the GCE surface, and consecutive SW voltammograms recorded in buffer always showed the same current for peak $3_{\mathrm{a}}$ (not shown).

Concerning DNA oxidation, it has been shown in experiments carried out in $\mathrm{pH} 70.1 \mathrm{M}$ phosphate buffer and in $\mathrm{pH}$ 4.5 0.1 M acetate buffer, that it occurs at lower potentials at physiological $\mathrm{pH}$, but in $\mathrm{pH} 4.50 .1 \mathrm{M}$ acetate buffer the DNA oxidation peak currents are several times higher [27]. This leads to lower detection limits in the identification of DNA oxidative damage and for this reason subsequent experiments were all carried out in $\mathrm{pH} 4.50 .1 \mathrm{M}$ acetate buffer.

\subsection{Analysis of Incubated Solutions}

Initial studies of the interaction between glivec and DNA were carried out by incubating a solution of $60 \mu \mathrm{g} \mathrm{mL}^{-1}$ dsDNA with $1 \mu \mathrm{M}$ glivec in $\mathrm{pH} 4.50 .1 \mathrm{M}$ acetate buffer. Then DP voltammograms were recorded after different incubation periods. The GCE surface was always renewed between consecutive measurements in order to avoid the 


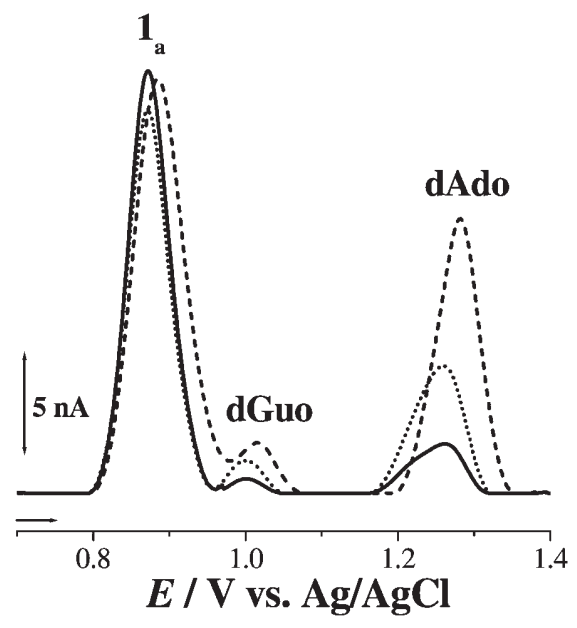

Fig. 2. DP voltammograms obtained with a GCE in a solution of $60 \mu \mathrm{g} \mathrm{mL}{ }^{-1}$ dsDNA incubated with $1 \mu \mathrm{M}$ glivec in $\mathrm{pH} 4.50 .1 \mathrm{M}$ acetate buffer after: (-) 1, ( …) 30, and (- - -) 120 minutes of incubation.

blocking of the electrochemically active surface by adsorption of the oxidation products of both DNA and glivec.

The DP voltammogram obtained immediately after the addition of glivec to the solution of dsDNA, Figure 2, full line, shows the glivec oxidation peak $1_{\mathrm{a}}$ and two more anodic peaks at $E_{\mathrm{pa}}=+1.00 \mathrm{~V}$ and $E_{\mathrm{pa}}=+1.26 \mathrm{~V}$. These two peaks correspond to oxidation of the purinic DNA bases, desoxyguanosine (dGuo) and desoxyadenosine (dAdo), respectively [28]. For longer incubation periods, higher dGuo and dAdo oxidation peaks were obtained. The increase of the DNA oxidation peaks occurs in a time-dependent manner and takes place during 2 hours of incubation (not shown). After this period, both dGuo and dAdo peaks reach a constant size.

The increase of dGuo and dAdo peaks is attributed to conformational changes in the dsDNA structure. The dsDNA structure makes access of the bases to the electrode surface difficult, hindering their oxidation. As the double helix unwinds, easier access of the bases to the surface leads to higher voltammetric signals [23-25]. On the other hand, small positive shifts of about $20 \mathrm{mV}$ of the oxidation potential of glivec are observed in Figure 2, also proving that an interaction between glivec and DNA had occurred.

Although the electrochemical experiments carried out in incubated solutions showed changes of the dGuo and dAdo peaks after interaction of DNA with glivec, the type of modifications occurring in the dsDNA structure needs to be understood. During voltammetric detection in the incubated solution, dsDNA and glivec adsorbed strongly on the GCE surface leading to blockage of the electrode surface. The peaks obtained could be due to oxidation of glivec molecules adsorbed on the GCE surface besides those complexed with dsDNA.

\subsection{In Situ Study of Glivec-DNA Interaction}

For a better understanding of the interaction between glivec and DNA, a dsDNA-multilayer electrochemical biosensor has been used (see Sec. 2.4). The electrode surface was characterized by MAC Mode AFM and the images revealed a complete surface coverage [27]. Consequently, undesired adsorption of glivec molecules on the electrode surface is not possible. The biosensor response can only arise from the interaction of the compound with dsDNA without any contribution from the diffusion process. Moreover, the DNA-biosensor will allow the electrochemical generation of glivec intermediates (metabolites) and the investigation of the interaction of glivec oxidation products with DNA.

The changes occurring to dsDNA during its interaction with glivec were followed by DPV, using the dsDNAbiosensor. The GCE modification procedure with multilayer dsDNA is described in Section 2.4.

The DNA-biosensor was incubated for 1 minute in $5 \mu \mathrm{M}$ glivec solution and then transferred to acetate buffer where DPV was performed, Figure 3, full line. As expected, the voltammogram obtained shows glivec oxidation peak $1_{\mathrm{a}}$ and the peaks due to the oxidation of DNA bases. The experiment was always repeated with a new biosensor, varying the incubation time, to 2 and 3 minutes of incubation (dotted and dashed line, respectively). Increasing the incubation time in the glivec solution, the glivec oxidation peak $1_{\mathrm{a}}$ also increases. The binding of glivec molecules lead to modifications of the dsDNA film and this is detected by the occurrence of increasing peaks for dGuo and dAdo, with incubation time. The changes taking place in the dsDNA conformation depend on the quantity of glivec bound to the immobilized DNA. This experiment also demonstrates that it is possible to preconcentrate glivec into the dsDNA film and, that even after interaction with DNA, glivec can still undergo oxidation.

After incubation with glivec, the dsDNA film was removed from the electrode surface and a DP voltammogram was recorded in buffer (not shown). No glivec

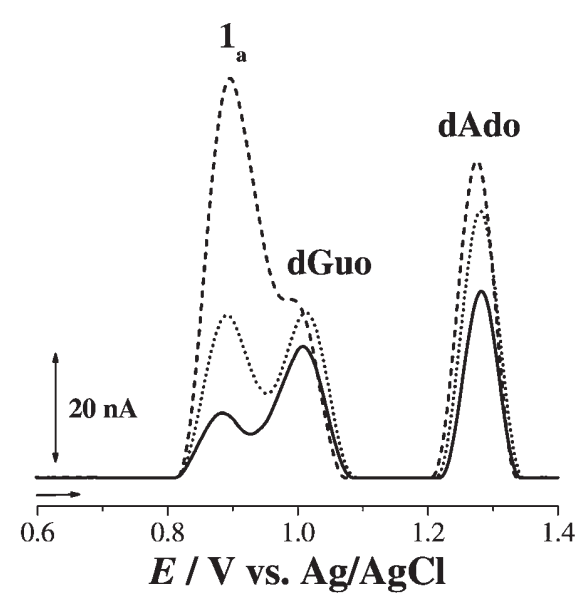

Fig. 3. DP voltammograms obtained with multilayer dsDNA biosensors in $\mathrm{pH} 4.50 .1 \mathrm{M}$ acetate buffer after incubation for: $(-)$ $1,(\cdots \cdots) 2$, and (- - -) 3 minutes in $5 \mu \mathrm{M}$ glivec. 
oxidation peak was observed, proving once again a complete coverage of the electrode surface after the modification procedure with dsDNA.

In another experiment, a new dsDNA-biosensor was held for 2 minutes in a stirred $5 \mu \mathrm{M}$ glivec solution. After this period, the biosensor was rinsed with deionized water and immersed into acetate buffer where a conditioning potential of $+0.90 \mathrm{~V}$ was applied during 1 minute. At this potential, the glivec molecules attached to the dsDNA film are oxidized leading to the formation of $\mathrm{P}_{\text {glivec }}$. Therefore, in the DP voltammogram recorded, Figure 4, dashed line, oxidation peak $1_{\mathrm{a}}$ of glivec occurred with a smaller current when compared with the voltammogram obtained without the application of $+0.90 \mathrm{~V}$, Figure 4 , full line. Also, the peak 3 a specific to $\mathrm{P}_{\text {glivec }}$ can be observed. Nevertheless, a new small peak occurs at $E_{\mathrm{pa}}=+0.45 \mathrm{~V}$. It must be remarked that glivec oxidation at the bare GCE surface does not give rise to any peak at $+0.45 \mathrm{~V}$, as already shown in Section 3.1, Figure 1A, dotted line. Also, the conditioning potential of $+0.90 \mathrm{~V}$ does not oxidize the immobilized DNA since the oxidation of guanine (the most easily oxidized DNA base) in $\mathrm{pH} 4.5$ solution occurs at a higher potential, e.g., $E_{\mathrm{pa}}=+1.01 \mathrm{~V}$. Therefore, the peak at $E_{\mathrm{pa}}=+0.45 \mathrm{~V}$ is caused by the interaction between DNA and the products formed during the oxidation of glivec. The appearance of this peak indicates the occurrence of products of DNA oxidative damage during the oxidation process of glivec.

The above experiment was repeated varying the time during which the potential of $+0.90 \mathrm{~V}$ was applied. The DP voltammogram obtained after conditioning the dsDNAbiosensor for 2 minutes is shown in Figure 4, dotted line. The glivec oxidation peak $1_{\mathrm{a}}$ shows a decrease with the conditioning time, due to glivec consumption. On the contrary, the $\mathrm{P}_{\text {glivec }}$ oxidation peak $3_{\mathrm{a}}$ and the peak at $E_{\mathrm{pa}}=+0.45 \mathrm{~V}$ show an increase with conditioning time.

For a better understanding of the results obtained, the electrode surface was also covered with a film of ssDNA. The modification procedure for the ssDNA-biosensor is

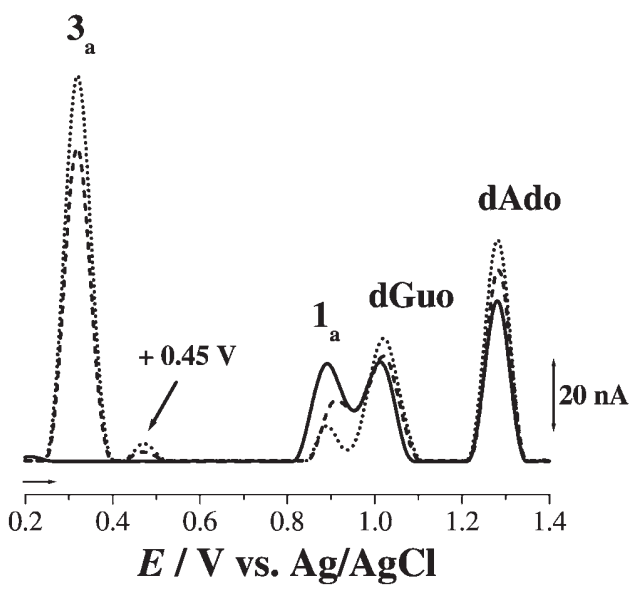

Fig. 4. DP voltammograms obtained with the dsDNA biosensor in $\mathrm{pH} 4.50 .1 \mathrm{M}$ acetate buffer after incubation for 2 minutes with $5 \mu \mathrm{M}$ glivec $(-)$ before and after application of $+0.90 \mathrm{~V}$ during $(---) 1$ and $(\cdots \cdots) 2$ minutes. described in Section 2.4. The DP voltammogram obtained after modification of the GCE surface with ssDNA, Figure 5, dashed line, shows the two peaks due to dGuo and dAdo oxidation. Subsequently, this ssDNA-biosensor was incubated with glivec: the voltammogram recorded, Figure 5, dotted line, shows the glivec oxidation peak $1_{\mathrm{a}}$. Also, the small increase of dGuo and dAdo peaks when compared with the voltammogram obtained before incubation, are explained taking into account the breaking of intrastrand hydrogen bonds between complementary bases of the ssDNA nucleotide chain. The application of $+0.90 \mathrm{~V}$ during 2 minutes to the ssDNA-biosensor previously incubated in $5 \mu \mathrm{M}$ glivec, Figure 5, full line, causes the complete oxidation of glivec molecules attached to the immobilized ssDNA and the formation of $\mathrm{P}_{\text {glivec }}$, peak $3_{\mathrm{a}}$. The peak at $E_{\mathrm{pa}}=$ $+0.45 \mathrm{~V}$ is again seen.

These experiments show that glivec also interacts with single stranded polynucleotides.

\subsection{In Situ Study of Glivec-Polyhomonucleotides Interaction}

In order to obtain more information about the origin of the peak at $E_{\mathrm{pa}}=+0.45 \mathrm{~V}$ observed after the oxidation of glivec previously bounded to DNA, several experiments using a GCE modified with polynucleotides of known sequences were performed.

First, the GCE surface was modified as described in Section 2.4 with a polyhomonucleotide that contains only residues of guanine, poly[G]. A DP voltammogram obtained in $\mathrm{pH} 4.50 .1 \mathrm{M}$ acetate buffer shows only a peak at $E_{\mathrm{pa}}=+1.02 \mathrm{~V}$, corresponding to dGuo oxidation, Figure $6 \mathrm{~A}$, dashed line. When a new poly[G]-biosensor was incubated for 2 minutes in $5 \mu \mathrm{M}$ glivec, peak $1_{\mathrm{a}}$, corresponding to the oxidation of the glivec molecules bound to the immobilized poly[G] strands, also appeared, Figure 6A, dotted line. When the poly[G]-biosensor previously incu-

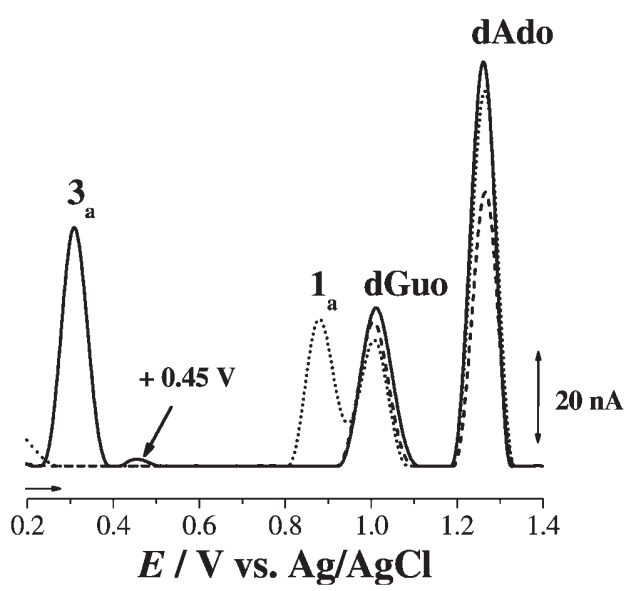

Fig. 5. DP voltammograms obtained with a multilayer ssDNA biosensor in pH 4.5 0.1 M acetate buffer (- - -) before and after incubation for 2 minutes with $5 \mu \mathrm{M}$ glivec $(\cdots \cdots)$ without and $(-)$ with the application of $+0.90 \mathrm{~V}$ during 2 minutes. 

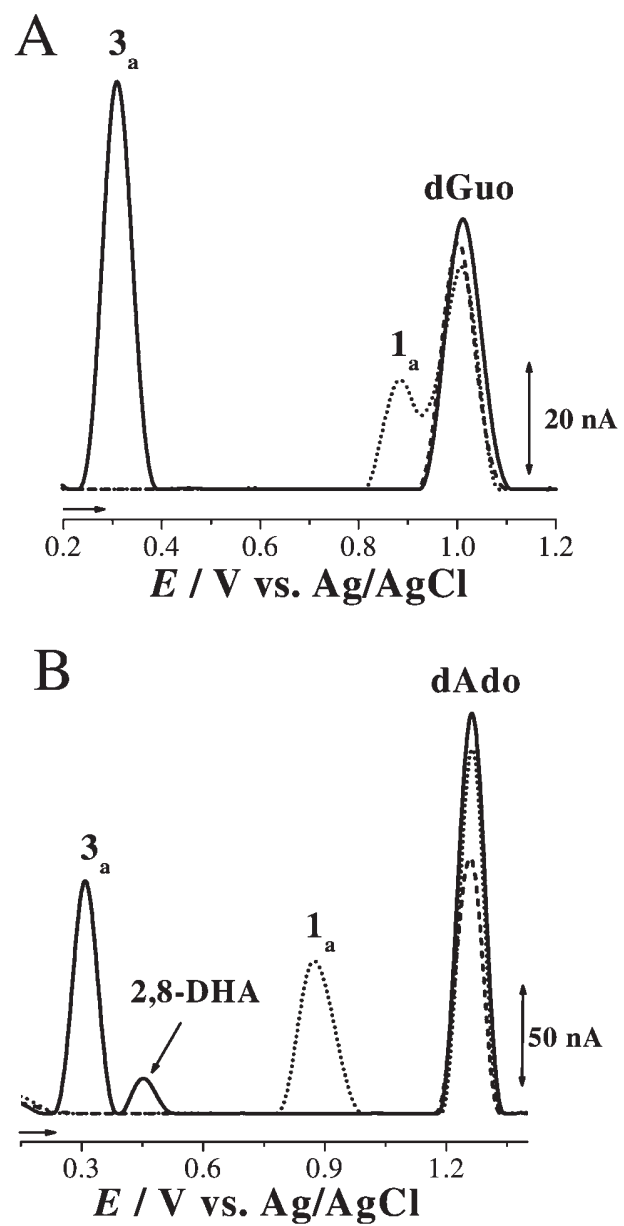

Fig. 6. DP voltammograms obtained with a multilayer A) poly[G] and B) poly[A] biosensors in $\mathrm{pH} 4.50 .1 \mathrm{M}$ acetate buffer (- - -) before and after incubation for 2 minutes with $5 \mu \mathrm{M}$ glivec $(\cdots \cdots)$ without and $(-)$ with the application of $+0.90 \mathrm{~V}$ during 2 minutes.

bated in glivec was conditioned for 2 minutes at a potential of $+0.90 \mathrm{~V}$, peak $1_{\mathrm{a}}$ disappeared due to the complete oxidation of glivec molecules, and the occurrence of peak $3_{\mathrm{a}}$ shows the formation of $\mathrm{P}_{\text {glivec }}$. However, no peak at $E_{\mathrm{pa}}=$ $+0.45 \mathrm{~V}$ was observed, Figure $6 \mathrm{~A}$, full line.

In the second series of experiments the electrode surface was modified in the same way with poly[A], a polyhomonucleotide that contains only residues of adenine. Therefore, the DP voltammogram obtained in supporting electrolyte shows only the peak dAdo at $E_{\mathrm{pa}}=+1.26 \mathrm{~V}$, Figure $6 \mathrm{~B}$, dashed line. A newly prepared poly[A]-biosensor was incubated in a glivec solution and the DP voltammogram obtained in buffer shows both dAdo and peak $1_{\mathrm{a}}$, Figure 6B, dotted line. The increase in the dAdo peak can be explained considering the unwinding of the double-helical structure of poly[A] in acid media [24,29]. After interaction with glivec, conformational changes take place in the immobilized poly[A] leading to a higher dAdo peak. On conditioning a previously glivec incubated poly[A]-biosensor at a potential of $+0.90 \mathrm{~V}$ during 2 minutes, the glivec molecules are all oxidized giving rise to $\mathrm{P}_{\text {glivec }}$, peak $3_{\mathrm{a}}$ Figure $6 \mathrm{~B}$, full line. In this case, the peak at $E_{\mathrm{pa}}=+0.45 \mathrm{~V}$ occurs with a higher current when compared with the same peak obtained at either dsDNA or ssDNA biosensors

These experiments using poly[G] and poly[A]-biosensors, clearly show that the peak at $E_{\mathrm{pa}}=+0.45 \mathrm{~V}$ is directly related with the oxidation of adenine residues on the DNAbiosensor and its potential corresponds to the oxidation of 2,8-dihydroxyadenine (2,8-DHA) [30], the main oxidation product of adenine.

However, when the biosensor is conditioned at $+0.90 \mathrm{~V}$, glivec is oxidized leading to formation of $\mathrm{P}_{\text {glivec }}$, which is electroactive and adsorbs very strongly onto the electrode surface. At the glivec oxidation potential both the oxidation of glivec and of the formed $P_{\text {glivec }}$ occur. Hence, it is difficult to distinguish the process that leads to the formation of 2,8-DHA. This can be overcome in the following experiment which investigates the interaction between $\mathrm{P}_{\text {glivec }}$ adsorbed at the GCE surface and poly[A].

Adsorption of $\mathrm{P}_{\text {glivec }}$ at the GCE surface was undertaken as described in Section 2.5. The GCE with adsorbed $\mathrm{P}_{\text {glivec }}$ was then placed in a solution containing $60 \mu \mathrm{g} \mathrm{mL} \mathrm{m}^{-1}$ poly[A] in $\mathrm{pH} 4.50 .1 \mathrm{M}$ acetate buffer allowing free adsorption to occur during 2 minutes. After washing with deionized water, the GCE was transferred to the supporting electrolyte where a potential that allows the oxidation of $\mathrm{P}_{\text {glivec }}$ ( $+0.35 \mathrm{~V}$ during 2 minutes) was applied. It is possible to observe the formation of 2,8-DHA on the voltammogram obtained, Figure 7, full line, at $E_{\mathrm{pa}}=+0.45 \mathrm{~V}$ (see inset).

On the other hand, the oxidation of $\mathrm{P}_{\text {glivec }}$ is a reversible process. The $\mathrm{P}_{\text {glivec }}$ adsorbed on the GCE is reduced when the electrode is conditioned during 2 minutes at a potential of $+0.20 \mathrm{~V}$. A higher 2,8-DHA oxidation peak is obtained on the DP voltammogram obtained after reducing the adsorbed oxidized $\mathrm{P}_{\text {glivec. }}$ Thus, it is necessary to reduce the oxidized $\mathrm{P}_{\text {glivec }}$ in order to be able to form 2,8-DHA.

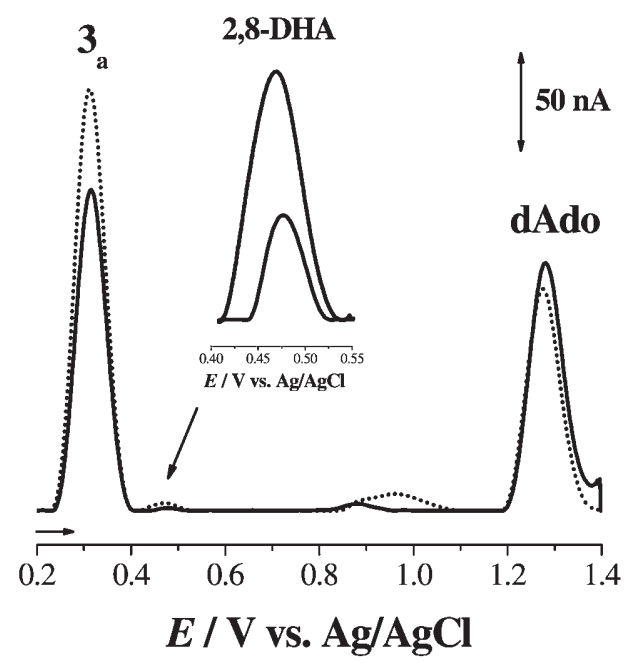

Fig. 7. DP voltammograms obtained in $\mathrm{pH} 4.50 .1 \mathrm{M}$ acetate buffer with $\mathrm{P}_{\text {glivec }}$ and poly[A] adsorbed at the GCE surface after application of $+0.35 \mathrm{~V}$ during 2 minutes $(-)$ without and $(\cdots \cdots)$ with conditioning the electrode for 2 minutes at $+0.20 \mathrm{~V}$ (for more details see Section 3.4). 


\subsection{Mechanism of Glivec-DNA Oxidative Damage}

The results presented give experimental evidence that glivec molecules interact with dsDNA causing distortion of the double helix. A schematic model for the interaction between glivec and DNA is proposed in Scheme 2. Electrochemical experiments carried out at an electrode modified with polynucleotides of known sequence lead to the conclusion that interaction between glivec and DNA occurs preferentially at adenine rich segments of DNA. Also, it has been demonstrated that glivec molecules can undergo oxidation even after binding to dsDNA.

Glivec is oxidized leading to formation of $\mathrm{P}_{\text {glivec }}$. At the glivec oxidation potential both the oxidation of glivec and of the formed $\mathrm{P}_{\text {glivec }}$ occur. The oxidation of $\mathrm{P}_{\text {glivec }}$ is a reversible process, and 2,8-DHA is detected only after reducing the adsorbed oxidized $\mathrm{P}_{\text {glivec }}$.

It is proposed that the electrons necessary to reduce the oxidized $P_{\text {glivec }}$ moieties are transferred from the adenine molecules. Electron transfer from the adenine moiety in DNA to the oxidized $\mathrm{P}_{\text {glivec }}$ gives rise to reduced $\mathrm{P}_{\text {glivec }}$ and leads to the formation of 2,8-DHA.

2,8 -DHA is the main adenine oxidation product and is the main clinical manifestation related to the metabolic deficiency of the purine salvage enzyme adenine phosphoribosyltransferase, which converts adenine from the nucleotide pool into adenosine monophosphate. In patients with this metabolic deficiency, the accumulated adenine is converted by xanthine dehydrogenase to 8-hydroxyadenine and then to 2,8-DHA. The precipitation and crystallization of $2,8-$
DHA can lead to stone formation in various parts of the urinary tract, leading to the loss of the kidneys.

\section{Conclusions}

A DNA biosensor was successfully used for the detection of the interaction between DNA and the antileukemia drug glivec. The DNA biosensor enabled the preconcentration of glivec onto the sensor surface. Monitoring the modification of guanosine and adenosine oxidation peak currents, it was concluded that glivec binds to dsDNA leading to modifications to the dsDNA structure, exposing more purinic residues to the electrode surface and facilitating their oxidation. Using polynucleotides of known sequences it was shown that glivec interacts with DNA especially at adenine enriched segments. By controlling the potential, the in situ electrochemical generation of glivec oxidation product inside the DNA double helix leads to the oxidation of adenine residues, and the detection of 2,8-dihydroxyadenine was possible.

The approach described can be used advantageously for the understanding of dsDNA interactions with various complex agents and individual chemicals of environmental, food and medical interest. The use of voltammetric techniques for the in situ generation of reactive intermediates is, in a successful way, a complementary tool for the study of biomolecular interaction mechanisms.

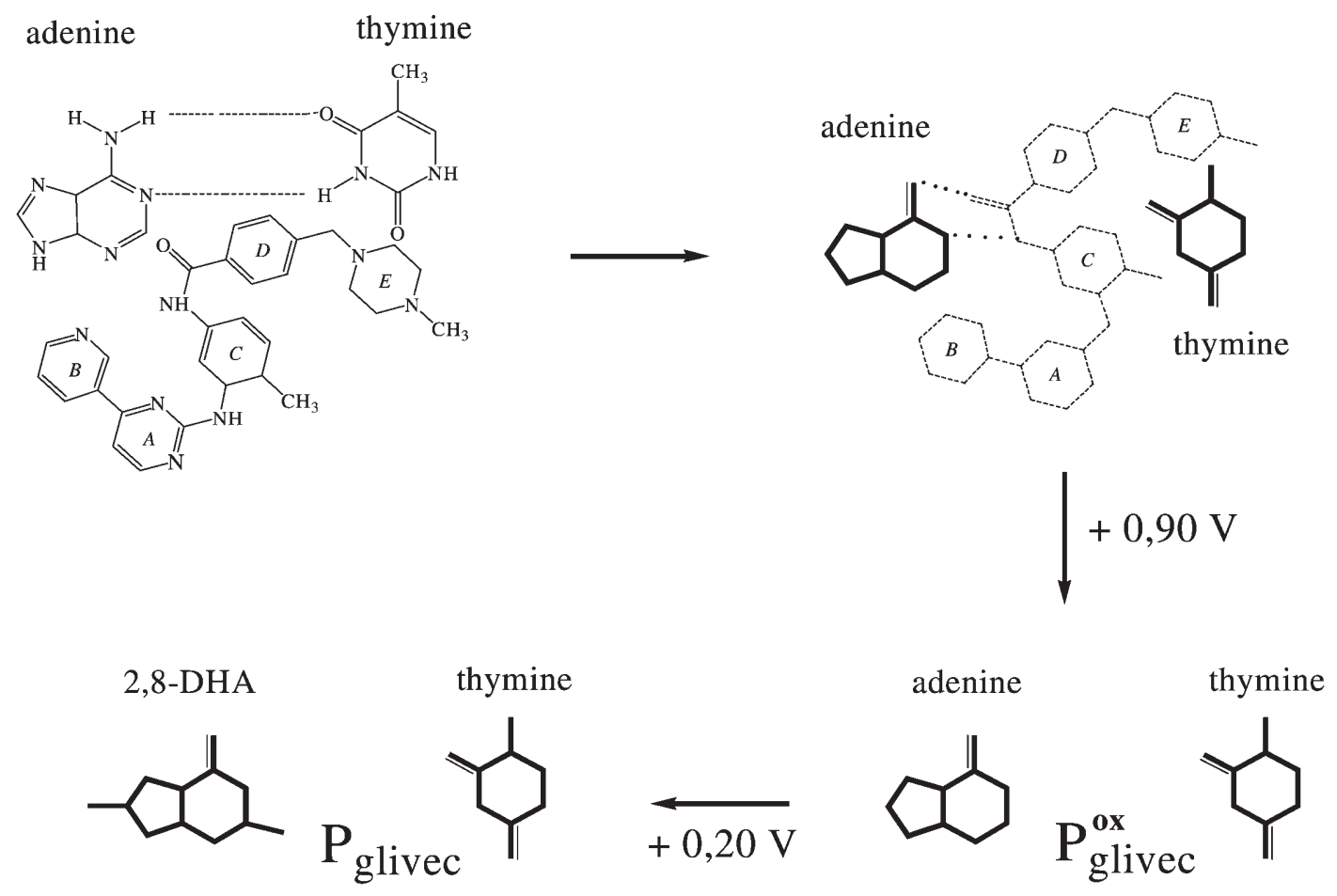

Scheme 2. Proposed interaction mechanism between glivec and DNA. 


\section{Acknowledgements}

Financial support from Fundação para a Ciência e Tecnologia (FCT), Post-Doctoral Grant SFRH/BPD/18824/2004 (V.C. Diculescu.), POCI (cofinanced by the European Community Fund FEDER), and ICEMS (Research Unit 103) are gratefully acknowledged.

\section{References}

[1] P. C. Nowell, D. Hungerford, Science 1960, 132, 1497.

[2] J. D.Rowley, Nature 1973, 243, 290.

[3] A. de Klein, A. G. van Kessel, G. Grosveld, C. R. Bartram, A. Hagemeijer, D. Bootsma, N. K. Spurr, N. Heisterkamp, J. Groffen, J. R. Stephenson, Nature 1982, 300, 765.

[4] Y. Ben-Neriah, G. Q. Daley, A. M. Mes-Masson, O. N. Witte, D. Baltimore, Science 1986, 233, 212.

[5] J. B. Konopka, S. M. Watanabe, O. N. Witte, Cell 1984, 37, 1035.

[6] L. Ramakrishnan, N. Rosenberg, Biochim. Biophys. Acta 1989, 989, 2209.

[7] R. Roskoski Jr., Biochem. Biophys. Res. Commun. 2003, 9, 709.

[8] B. J. Druker, N. B. Lydon, J. Clin. Invest. 2000, 5, 3.

[9] J. A. Kim, Am. J. Surg. 2003, 186, 264.

[10] E. Buchdunger, J. Zimmerman, H. Mett, T. Meyer, M. Muller, B. J. Druker, N. B. Lydon, Cancer Res. 1996, 56, 100.

[11] The Glivec International Site, http://www.glivec.com/about

[12] R. Bakhtiar, J. Lohne, L. Ramos, L. Khemani, M. Hayes, F. Tse, J. Chromatogr. B 2002, 768, 325.

[13] J. R. Flores, J. J. Berzas, G. Castaneda, N. Rodriguez, J. Chromatogr. B 2003, 794, 381.
[14] R. A. Parise, R. K. Ramanathan, M. J. Hayes, M. J. Egorin, J. Chromatogr. B 2003, 791, 39.

[15] R. Bakhtiar, L. Khemani, M. Hayes, T. Bedman, F. Tse, J. Pharm. Biomed. Anal. 2002, 28, 1183.

[16] D. Ivanovic, M. Medenica, B. Jancic, A. Malenovic, J. Chromatogr. B 2004, 800, 253.

[17] G. Guetens, G. De Boeck, M. Highley, H. Dumez, A. T. Van Oosterom, E. A. de Bruijn, J. Chromatogr. A 2003, 1020, 27.

[18] A. Czechowska, T. Poplawski, J. Drzewoski, J. Blasiak, Chem.-Bio. Interact. 2005, 152, 139.

[19] S. Stroobants, J. Goeminne, M. Seegers, S. Dimitrijevic, P. Dupont, J. Nuyts, M. Martens, B. van den Borne, P. Cole, R. Sciot, H. Dumez, S. Silberman, L. Mortelmans, A. van Oosterom, Eur. J. Cancer 2003, 39, 2012.

[20] P. Zhang, W. Y. Gao, S. Turner, B. S. Ducatman, Mol. Cancer $\mathbf{2 0 0 3}, 2,1$.

[21] J. Li, J. Kleeff, J. Guo, L. Fischer, N. Giese, M. W. Büchler, H. Friess, Mol. Cancer 2003, 2, 32.

[22] M. Fojta, T. Kubicarova, E. Palecek, Biosens. Bioelectron. 2000, 15, 107.

[23] A. M. Oliveira Brett, M. Vivan, I. R. Fernandes, J. A. P. Piedade, Talanta 2002, 56, 969.

[24] A. M. Oliveira Brett, V. C. Diculescu, Bioelectrochemistry 2004, 64, 143-150.

[25] V. C. Diculescu, A. M. Oliveira Brett, Anal. Lett. 2005, 38, 2525.

[26] J. Osteryoung, R. Osteryoung, Anal. Chem. 1985, 57, 101A.

[27] V. C. Diculescu, A. M. Chiorcea-Paquim, A. M. Oliveira Brett, Sensors 2005, 5, 377.

[28] A. M. Oliveira Brett, J. A. P. Piedade, L. A. da Silva, V. C. Diculescu, Anal. Biochem. 2004, 332, 321.

[29] V. Brabeck, G. Dryhurst, J. Electroanal. Chem. 1978, 91, 219.

[30] V. C. Diculescu, J. A. P. Piedade, A. M. Oliveira Brett, Bioelectrochemistry 2006, in press. 